Fred Wilson

\title{
UNIVERSALS, PARTICULARS, TROPES AND BLOBS
}

Abstract. This study explores how to do ontology within a positivist framework, and specifically the issue of universals and particulars. It is argued that universals and bare particulars are pieces of commonsense within this framework. It is argued further that a nominalism of tropes makes no ontological sense within this framework, and that its degenerate form as a nominalism in which the world is an amorphous lump or consists of mere blobs is simply silly. Bergmann, Sellars, Moore, Stout and Hochberg are among the philosophers discussed.

Everyone at some time or other considers model universes, so we can start there also. But we want to consider our model in much the same way as we consider the world in which we actually live, that is, as a world which we have experienced. Our model is a world in which the things that are there are in the first instance things that we have encountered in our experience of the world - our sensible experience of the real, everyday world. (There is also inner awareness and the things that it assures us are there, also in the world, but we need not consider entities of these sorts for what we are about). Now think of an apple, as we really encounter it, an apple which is green on the one side and red on the other. Think of looking at it with the red side before us and the green side away from us. As we experience it there is a red expanse, bounded by a certain shape, and rather bulgy. Even if we know that the other side is green, that green is not given to us in our sensory experience. The model universe is like that red expanse. The things in this universe are simple expanses which have sensible features, sensible qualities and sensible shapes. Two of the expanses are red and circular, the other is green and square. Now, back in the real world of apples and other ordinary things, suppose there are three apples, two red, one green, arranged in a straight line with the green one between the two red ones. The parts of the apples that we sensibly experience are on this line. We can imagine the same thing for the expanses in our model universe. So, in our model universe let us suppose our three expanses ordered just as the sensible appearances of the apples appear in an order. Let us suppose that the green expanse is between the two red ones. 
There is nothing that could be thought puzzling about this universe, save its size. For, there is nothing puzzling about coloured expanses or patches. As G.F. Stout once put it,

I may, in double vision, have two images of a single candle flame. Then there appear or seem to be two candle flames, whereas in fact there is only one. But the visual presentations do not merely seem to exist and be separate. Both they and their separation really appear, are really presented or given, and must therefore really exist. It is only because the images really exist and are really separate that there appear or seem to be two candle flames. (Stout, 1930, p. 390)

In this sense, as he says, «... nothing can really appear except what really is, and really is as it appears» (Stout, 1930, p. 390). Our patches are somewhat elementary as things, if you wish, but they are just things like these images that Stout describes: they are sensible, they are locally separate, and they have various sensible properties.

It is also worth noting that the things in this model universe have sensible properties. Indeed, so do things in the real world. These properties are given to us in experience. It is as we experience them that I want to consider these things and their properties. Thus, for example, while the things in this universe fall into various sets - and there is also the empty set into which none of them fall - and, indeed, all those things which are red form a set - the set of red things -, the point to be made is that the properties as we are going to consider them are not merely sets of things: the things in this world are experienced as having sensible properties, and not as members of sets. It is things and their properties in which we are interested, not the sets, the bare collections, into which those things arrange themselves.

So let us consider a model universe in which there are, first, two red patches both of which are circular. Let us suppose that the colour of the one is indistinguishable from the colour of the other, and that the shape of the one is indistinguishable from the shape of the other. Next, there is a green patch which is square. Here the colour of this expanse can be distinguished from the colour of the other two. The shape can also be distinguished. But we need some names. We have three things: let us call the two red things "Cebes" and "Simmias" and the green thing "Socrates".

So we say of both Cebes and Simmias that they are red. It is sometimes said that there is a difficulty here, that there is a "problem of sameness": in virtue of what, it is asked, are they both called the same? In virtue of what do we make the same predication "Cebes is red" and "Simmias is red" of the two things Cebes and Simmias? Well, to this is the answer not obvious? In the world as we experience it, there is a property in Cebes that 
we have decided to refer to with the term 'red'. Having made that decision, we note that in the world as we experience it there is a property in Simmias that is indistinguishable from the property in Cebes that we have decided to refer to using the term 'red', so the property in Cebes is the same as the property in Simmias - the same in the sense of 'indistinguishable' - and we therefore apply the same term, and predicate 'red' of Simmias just as we predicate 'red' of Cebes. Cebes and Simmias are the same by virtue of the fact that there is present in the one a property that is indistinguishable from one of the properties in the other. Taking the properties in things to be the same when they are indistinguishable, things turn out to be the same just in case each has a property that is the same as a property present in the others.

In the world as we experience it, then, the same property can be in several things. But in traditional terminology, if a property can be present in several things, then that property is a universal. Here is the solution to the problem of sameness. Things are the same in the sense of having the same term predicated of them by virtue of the fact that properties are universals, and the same property can be present in several things: properties as universals solve the problem of sameness.

This is how Bergmann approached the problem of sameness ${ }^{1}$. He began with the logical positivists. Their programme was to clarify and to defend empirical science after the fashion of Mill and Comte and Mach, but to improve that defence by showing more clearly the logical structure of the language of science. The framework for this elucidation of the logic of science was that established by the developments of a newer, more adequate logic, the logic to be found in the formal language of Principia Mathematica. The aim was to explore the logic of scientific theories. Generally speaking, science is of course empirical: it is about the world as we experience it. The formal language was to be used to describe the world, and present to us the logical form of the theories that science developed and to validate the inferences made in science. So to do this, nonlogical or descriptive constants had to be added to the language of logic.

${ }^{1}$ Cf. Bergmann, 1944, pp. 209-211. Note the insouciance with which he mixes talk of predicates and of characteristics (the latter can be "undefined" - p. 209 -; but surely the notion of definition applies to linguistic items, namely predicates, and not the entities to which they refer). Note, also, the equal insouciance with which Bergmann (p. 210) speaks of characteristics as "universals" on the basis of the fact that a term referring to a characteristic can appear in several sentences which truly describe the world. 
These constants would refer to what is in the world as we experience it: how else could it validate logical inferences about what is in the world? how else could it show the logical structure of scientific theories? how else could science be defended against its critics? ${ }^{2}$

It is these constants that enable one to describe the world. To do this, they must be somehow hooked to the world: to the syntactical structure of the language must be added a semantics. This semantics must be such that sentences in the language can be used to describe the world as we experience it.

As in the real world, so in our model world, red is a feature that recurs. Our language must be such that this fact finds a representation in the language. We therefore, let us say, let the constant ' $R$ ' pick out this feature that recurs. But this alone will not do, not even for our model world: for, red occurs or recurs twice. In fact, it recurs with another features that also recurs, specifically a shape. Let us pick out this feature with the constant ' $C$ '. Moreover, these two features occur or recur together; in our world, as often in the real world, they are with one another. Let us represent this sort of connection with the constant ' $W$ '. Thus we have as an attempt to describe our model world, or at least parts of it, the sentence that

$\mathrm{W}(\mathrm{R}, \mathrm{C})$.

If we make, in the language of Principia Mathematica, ' $\mathrm{R}$ ' and ' $\mathrm{C}$ ' to be of the lowest type, then we should make ' $\mathrm{W}$ ' to be of the next higher type, so that it can represent, not features that occur and recur, but the way in which those features occur and recur in the world. Constants of the lowest type represent features that occur in the world, constants of the next higher type represent the way or ways in which those features occur or recur.

Two other features of our model world also have to be recorded. There is the feature we call "green" and that which we call "square". These are clearly distinguishable from the features we have labelled ' $R$ ' and ' $C$ '. Let us label them ' $G$ ' and ' $S$ '. And we note that these features are, like the features $\mathrm{R}$ and $\mathrm{C}$, with one another. That is, to describe our little world we also have

$\mathrm{W}(\mathrm{G}, \mathrm{S})$.

But we also have to note that there are features of our world that we have not yet recorded in our language. We have not yet noted that there are

${ }^{2}$ Cf. Bergmann, 1944; also Bergmann, 1942. In a note to the latter, Bergmann mentions philosophical discussions he had had with Wilfrid Sellars, whom he thanks for the vigorous debate. 
two expanses which are $\mathrm{R}$, red, and another, third expanse which is green. These expanses are distinguishable from the features we have already recorded in our language, and distinguishable from one another. Let us therefore have the constants ' $\mathrm{X}$ ', ' $\mathrm{Y}$ ' and ' $\mathrm{Z}$ ' pick out these three further features of this world.

These expanses go with the other features in the world in several ways. We record these ways the world is by the sentences

$$
\mathrm{W}(\mathrm{X}, \mathrm{R}, \mathrm{C}) \quad \mathrm{W}(\mathrm{Y}, \mathrm{R}, \mathrm{C}) \quad \mathrm{W}(\mathrm{Z}, \mathrm{G}, \mathrm{S})
$$

These sentences, through the ways in which the terms are organized into these sentences, picture the ways in which features go together or are with one another in our model world. Cebes is one of the ways in which the features go together in our model world, Simmias is another, and Socrates is a third.

This is just one of the many ways in which one can go about constructing language to make it fit for describing the ways in which the world is. One might also, for example, represent the expanses by constants of the lowest type and the other features by constants of the next higher type, and represent one feature being with an expanse by a sentence of the sort

RX.

In that case, what we before represented by the sentence ' $\mathrm{W}(\mathrm{X}, \mathrm{R}, \mathrm{C})$ ' ' is now represented by

RX

and

CX

taken together. That is, that red and circular are with the X-expanse is now represented by, in effect,

RX \& CX.

Being with one another is now not represented by a single term juxtaposed to three other terms, but rather is represented by two juxtapositions and an ampersand sign, or, if you wish, by two juxtapositions of constants and the juxtaposition of two sentences. In any case, we now have our model world represented by

RX, CX, RY, CY, GZ, SZ.

These are simply two different conventions for representing features in our model world and the ways in which those features occur and recur in that world. Both sets of conventions conform to the logical or syntactical 
structure required by Principia Mathematica. Bergmann in fact chose the second way to represent the ways the world is. But that is not the present point: either way would do. Either way can give pictures that represent the three things in our model universe, Cebes, Simmias, and Socrates - the three ways in which the distinguishable features in this universe go together, how they are with one another.

The point that needs to be made is this: In the world as we experience it, there are various distinguishable features that occur and among them some that recur. They recur in the sense that among two or more of the ways in which the world is, there is a feature in one of these ways that is indistinguishable from a feature in another of the ways the world is, or perhaps several other of the ways the world is. In our model, the feature represented by $\mathrm{R}$ occurs once with the expanse $\mathrm{X}$ and, indistinguishably, once with the expanse $\mathrm{Y}$. As one says, the feature that occurs with $\mathrm{X}$ is one with the feature that is with $\mathrm{X}$, they are the same. That is what indistinguishability amounts to: and that is why we say both expanses are red, and why in our structured language we apply the same term ' $R$ ' to that feature that is with $\mathrm{X}$ as we do to that feature that is with $\mathrm{Y}$.

All this is common sense, and unproblematic. In constructing the outlines of the language that is needed for the logical analysis of the language of science, one hardly notices it. It is important, but something that one can take for granted as one gets on with the further tasks required for the defence of science.

Now let us suppose that a philosopher working within this common sense context starts to read philosophers such as Russell or Moore. Here is another tradition, using language to do something other than, or something more than, explore the logic of science. This other tradition takes up issues that have their roots in patterns of thought that deal with other issues.

It turns out on this other tradition that world as we experience it and as that which our language is about consists of entities. And these are simple and complex - the descriptive constants are labels of simples, while sentences represent complexes. Complexes are made up of simples, simples are constituents of complexes. The features that have been labelled 'red' and 'green' and 'square' and 'circle' are properties. These are simple entities, and they occur in complexes. Indeed, as it turns out, in our model universe as in the real world, there are no simples that are not in complexes. Moreover, the feature labelled 'red' is one that recurs as this property red in several different complexes; that is what happens when one uses the term 'red' to apply to a given feature - one re-applies the same 
term when there is a feature elsewhere that is indistinguishable from it. This piece of common sense becomes the truth that the same property can occur and recur in several different complexes.

Thus, the piece of common sense about the language of science and about how, in constructing that language, we use linguistic labels to pick out discernible features that occur and recur in the world as we experience it turns out to be a not unimportant truth in metaphysics, and in particular in ontology, which is that part of metaphysics that deals with what is, that is, what things or entities that are and the categories of things that are. Traditionally, if one holds that one and the same property can be in several different things, then one is holding the realist position that properties are universals, they are realized, and realized multiply, in diverse complex things in the world. That is, the world as we experience it.

Or rather: When one first comes across them, metaphysical claims are puzzling. What does it mean to say that entities are simple or complex chairs have parts but are the legs which are parts also simple? and what about the sensible expanses of our model world, do they also have parts? Metaphysics says that they do, but those parts are certainly not like the parts of a chair. And what does it mean to say that some among the simple entities in the world as we experience it are universals? are there universals alongside chairs or alongside coloured expanses or alongside oysters or alongside rainbows? I can bump into a chair, and I can eat an oyster, and I can experience a coloured patch, and I can contemplate a rainbow: can I do any of these things with universals? But now our philosopher has discovered something - something important. When one reflects on the common sense way in which language is fit onto the world, then we discover that the metaphysical claims can be understood as claims about this language and how it fits onto the world. The metaphysical claims that puzzle us can be explicated, rendered as unproblematic common sense common sense about how we fit language onto the world - how we fit the language of the empiricists and the logical positivists onto the world. So the ontological claim which we find puzzling to the effect that there are, among the simple entities in the world, universals becomes the piece of common sense that there are in the world as we are acquainted with it in our sensible experience, features that we label with descriptive constants, and some of these occur and indistinguishably recur - it is these features that we call "universals". 
What makes the claim that there are universals true is nothing more than the claim, for example, that there are two red shirts, or the claim about our model universe that there are two red patches.

Note how this commonsensical approach sets to one side as coy silliness certain claims that talk about universals is simple metaphysical nonsense, claims that quite literally are quite without any cognitive sense. Thus, David Lewis for one has said that

I have complained about the difficulty of understanding the relation that allegedly relates concrete things to the abstract simple possibilities - propositions or properties - that they realize.

[...] It's a nasty predicament to claim that you somehow understand a primitive notion, although you have no idea how you could possibly understand it [...] that's the predicament I claim others are in if they accept the alleged notion of realization of abstract simple possibilities. (Lewis, 1991, pp. 35-36)

How properties come to be "abstract" is not explained. In fact, it is perfectly clear that properties are there among the entities in the world as we experience it: they may not be "concrete", whatever that is, but if 'abstract' means 'abstracted from', where to be abstracted from something means to be separated from it, then properties are certainly not abstract: they are simply features of the world as we experience it that occur and recur and just for that reason are realized in the things of our world. And what exactly is meant by a "proposition"? Since it is coupled with "property', it likely means something like a complex whole represented by a sentence, the state of affairs that is meant by, and is, if you wish, the meaning of a sentence, in contrast to the simple properties which are meant by constants such as 'red'. But we aren't told: essentially Lewis is simply obfuscating things by sloppy and misleading use of language. He should try explicating metaphysical claims, making them commonsensical, instead of making them more puzzling than they ordinarily are by the sloppy undoubtedly deliberately sloppy - use of language. Whatever he means by what he is saying, he is evidently trying to make the point often made by others that they do not understand what it is for one entity to be present in, or realized, in several diverse things. What these philosophers are saying what it is likely Lewis is saying in his obfuscating way - is that metaphysical claims are intrinsically puzzling, and in particular the claim that properties are universals and that these universals can be realized in many things is a puzzling claim without any clear sense.

But our philosopher - our positivist who has learned how to do ontology - has found a way out of this predicament: explicate the problem so that its solution can be found as a way of speaking about the language we create in 
order to describe about the world as we experience it. Explicated, it turns out that to say that there are universals that are realized in or by various diverse things in the world is to say that, for example, the feature we call 'red' occurs and recurs in various ordinary things. The ontological claim is no more puzzling than the claim that there are two shirts or two expanses such that each has a feature that is indistinguishable from a feature had by the other and that we call this feature by the term 'red'. Who can be puzzled by the fact that one has two shirts which are both red or two patches which are both red? Again, let us not be coy: our philosopher has shown us how to make these puzzling things common sense, perfectly intelligible claims about the world as we experience it.

Our philosopher who started out as a positivist who takes all metaphysical claims to be nonsense - someone more or less like Bergmann - has thus found out - prodded by Russell and Moore and perhaps in some complicated way by Wittgenstein ${ }^{3}$ - how to do ontology: one takes the puzzling metaphysical claim and transforms it into a piece of common sense by explicating it as a claim about the language we construct as we attempt to defend science. Defend science? But against what? Against metaphysics, of course. But that is, as it now turns out, against those claims of metaphysics that cannot be explicated as commonsensical truths about the language of science. There are universals - that is now common sense; but that does not mean that suddenly we have a way of conferring meaning on metaphysical claims to the effect, for example, that there is a God who created the universe and gave us an immortal soul, which is tainted to be inevitably evil through the presence in that soul of the effects of the original sin of pinching an apple from someone who made it for himself but who turned out not really to need it because, as it happened, he was self-sufficient and dependent on nothing. Our philosopher is still a positivist, but a positivist who has come to be an ontologist. Or better: the positivist has discovered how to be both a positivist and an ontologist.

So, there are properties which things have and these properties are universals. However, not everyone is comfortable with this claim. I am thinking of those philosophers who argue that the properties of things are not universals. Things do have features that we can, in our experience of the world, notice. We even call them by the same name. But that is ontologically misleading. In fact, it is claimed, the feature in Cebes that we label with the term 'red' is distinguishable from the feature in Socrates that we label 'green', while there is a feature in Cebes and one in Simmias that

${ }^{3}$ And no doubt by conversations with Everett Hall and Wilfrid Sellars. 
we label with the term 'red', where we apply the same term because the feature in Cebes and the feature in Simmias are in that way indistinguishable: they are, in other words, the same, where, in contrast, this feature is different from that other feature in Socrates, and, indeed, is different from all the other features or properties in our model universe. But the philosophers that we are now considering, while granting that the feature of Cebes that we label 'red' is the same as the feature of Simmias that we also label 'red', also argue that there is a sense in which we in fact have two features that are different from one another: they are the same, that is, not different, in the sense of being indistinguishable, while in another sense of the term 'different', they are different - the red in Cebes is the same as the red in Simmias while nonetheless they are also different - there are two reds and not just one. Properties are not universals. Properties, while they recur in the sense of being indistinguishable from one another, never actually recur: every occurrence of a property is different from every other occurrence. These properties that differ on their every occurrence are what these philosophers call "tropes". And since the defender of tropes denies what the realist claims, that they are universals, such a one can correctly be said to be a nominalist ${ }^{4}$.

The nominalist holds that no two things have sensible features that are the same. Some are indistinguishable in respect of some feature, say red, to continue with our example - they are qualitatively indistinguishable we may say. But they are nonetheless different, the nominalist holds: the red in Cebes while apparently the same as the red in Simmias is not the same as the red in Simmias, and the circle in Cebes, while apparently the same as the circle in Simmias, is in fact different. These differences are delivered to us in our experience of the world - or at least that is what the nominalist should say if he or she is trying to describe in a perspicuous way features and the ways features are in the world as we experience it.

The nominalist holds that the red in Cebes is different from the red in Simmias - we have as two entities Cebes-red and Simmias-red -, nonetheless the two reds are in fact indistinguishable: although they are not the same they are still exactly similar in their redness - this is given to us in our experience of the world. It could be suggested that the two reds are simple entities. But then, why are they also the same? Some suggest that the fact that they are both reds is a matter of their standing in a relation of exact similarity.

\footnotetext{
${ }^{4}$ For further discussion of many of these points, cf. Wilson, 2007a.
} 
It could be argued that this relation of exact similarity is an internal relation, where this ontological status is reflected in language by the fact that tropes are represented by terms like 'Cebes-red' and 'Simmias-red', or 'this-red' and 'that-red', or ' $\mathrm{red}_{1}$ ' and ' $\mathrm{red}_{2}$ '.

But surely, one must reply to this suggestion, to represent the feature by a complex name like 'Cebes-red' and 'Simmias-red' or by ' $\mathrm{red}_{1}$ ' and ' $\mathrm{red}_{2}$ ' is to allow that there is a feature of Cebes with respect to which it is indistinguishable from the corresponding feature in Simmias. When the nominalist uses such a term to say that Cebes is red, then what he or she says is that

Cebes is Cebes-red,

which draws attention to the very same feature to which the realist draws attention when he or she says that

Cebes is red.

The nominalist is representing the very same way the features of the world are with one another as is the realist, only he or she is doing it with terms which are special or oddly different. Speaking of an "internal relation" simply obscures this fact. That is, it obscures the fact that there is a feature of Cebes which is indistinguishable from a feature of Simmias, a feature which they therefore share. Which is all that the realist claims: when he or she claims that red is a universal (and so also that other properties are universals), all that is being claimed is that the two things have a feature with respect to which they are indistinguishable.

The nominalist thus cannot claim that he or she can be distinguished from the realist by virtue of his or her tropes being supposedly different but the same insofar as they are internally related since that supposed internal relation is nothing but the feature which, on the realist's way of speaking, and of representing things, is something common to several things or at least something which can be shared by several things. Wishing nonetheless to save the tropes as being different yet the same yet not sharing a common feature, the nominalist may hold that two tropes, e.g., two reds, are simply different yet are related by an external relation of exact similarity.

But it is not too hard to see that this nominalist is after all committed to realism, that he or she cannot avoid universals. Russell so argued ${ }^{5}$.

He pointed out that on the view that exact similarity is an external relation the circle in Cebes is exactly similar to the circle in Simmias just as

${ }^{5}$ Russell, 1956. Cf. also Stout, 1930, pp. 388-390. 
the red in Cebes is exactly similar to the red in Simmias. The relation of exact similarity is the same in the two cases. It is, therefore, a universal. But if one is going to admit one universal, one might as well have others (cf. Hochberg, 1984). So the nominalism turns out to be a sort of realism: it after all does admit universals.

But surely there is a simpler point to be made. For, surely, to say that the two reds are exactly similar says nothing very different than saying that the two reds are indistinguishable. Which is the same as saying that the two complexes of which the two reds are parts each have a feature where the feature in the one complex is indistinguishable from the corresponding feature in the other complex. And that is to say that they do after all share a feature, and the nominalist's attempt to avoid universals fails.

It would seem, then, that so long as the nominalist holds that what makes two tropes indistinguishable in kind, what grounds their sameness, is something that is presented to us in our experience of the world, then there is little to distinguish his or her position from that of the realist.

There is another way, however, for the nominalist to avoid universals as entities given in sense, and that is by arguing that what accounts for the sameness and difference of tropes is not known by sense at all. The nominalist can distinguish his or her view about why ordinary things are the same and different as others if he or she argues that what grounds the sameness of the tropes is not something given in sense. Stout, at times at least, seems to be a nominalist of this sort. Certainly, he tells us that «in mere acquaintance, we do not know the thing exists or what it is: we do not distinguish it from other things or from its qualities» (Stout, 1930, p. 393). What makes a concrete thing to be of a certain kind «presupposes that, in some sense, a plurality of things share in a common character», by which is meant that «each is characterised by a particular instance of a general kind or character» (Stout, 1930, p. 396). Resemblance of characters is not a relation; it «presupposes a complex unity of the peculiar type which I [Stout] call the distributive unity of a class» (Stout, 1930, p. 388). There is something which grounds this unity but it is not a relation and is not given in acquaintance, that is, in our sense experience of the world. In this respect Stout's view is akin to that of Plato. Certainly, Plato is a nominalist (see Theatetus; Plato, 1987), for he holds that the entities that are known by sense are all such that «each of them is different from the other but the same as itself...» (Theaetetus, 184a10). This includes the properties of things, things such as, e.g., our Cebes and Simmias are, of course, known by sense: thus, «the mind perceive[s] the hardness of something by means 
of touch», and so on for other sensible properties of things. It follows, Plato holds, that the red in Cebes and the red in Simmias are different from one another, which creates what is for him the problem of sameness. For, why the two things are the same, why they are similar in colour, and indeed why the colour in these two things is different as a colour from the green in Socrates, are all not given in sense. Why, therefore, do we reckon the property in Cebes as the same as the property in Simmias? In fact, the colour properties of the three things are all different as localized at three separate places, and in trying to say why there are two reds and a green Plato has for himself a problem. Plato argues that besides the localized properties, the tropes, there are non-local properties in which these tropes participate which account for the sameness of these tropes. These are the forms that account for the sameness of the two reds and the difference of these from the trope which is green. Cebes is red because it has a character that participates in the form of red, and Simmias is red because of the character in it that participates in the same form of red, while Socrates is green because it has a character that participates in a different form, the form of green. The forms account for what Cebes is, and why it is the same and different as other things. But these forms are not given in sense. Plato argues that they are known another way: in his terms they are known by the mind as such, the mind "by itself" as he speaks. As he puts it with regard to these forms, «their being (that is, that they both are)» and their «similarity, dissimilarity, identity and difference» are all «in the class of things which the mind gets at by itself» - with regard to their being, what they are in themselves and relative to other forms, «the mind by itself has the job of reaching a decision by reviewing them and comparing them with each other» (Theaetetus, 186b10).

There is a problem here, for both Plato and Stout. Tropes are given in sense, we are acquainted with them. Forms we are not given in sense, we are not acquainted with these entities which account for why tropes are the same and different in kind; they are known by the "mind by itself". But if the sameness of two tropes is not given in sense but only in some other way, then we have the relationship that the red in Cebes participates in the form of red, and the question immediately arises, or should immediately arise (though unfortunately it more often does not arise), how do we know this fact? Indeed, what is it that we know when we know what we know when we say that the property in Cebes and that in Simmias are both reds? We know the tropes one way and the forms another way, but what we also have to know is the complex of this trope, the red in Cebes, participating in 
the form red - the complex represented by the statement that "Cebes-red is red". Besides the eye of the senses which gives us the sensible world, the tropes, and the eye of the mind which gives us the forms, we need a third eye to cognize how the materials of sense come together with the materials furnished by the acting "by itself". But no philosopher has ever convincingly argued that we do in fact have a third "eye". Certainly not Plato and certainly not Stout: neither of them provides a solution to this problem.

Indeed, they really do not tell us what the second sort or way of knowing is, how this special eye of the mind which we are all supposed to have really works. They claim that it exists and that through it we know those entities that ground the sameness and difference of tropes, but we are not told how precisely we are to get hold of this form of knowing. What is this mind that by itself gives us non-sensory knowledge of certain entities, entities which are themselves puzzling?

There is, however, a deeper point about this sort of nominalism. It seeks to defend tropes by separating them from the entities, the forms or what have you, that make them the same and different from other tropes, and holding that while the tropes are given in sense, these other entities are not and are known in some other non-sensory way. This means that the world as we ordinarily experience it contains nothing that grounds the sameness and difference of things. The red in Cebes is given in sense but not that which makes it $a$ red. It follows that so far as sense is concerned the characteristics of things are devoid of kinds, they are simply little blobs. Which surely is a point of view that is not just puzzling but quite unacceptable.

This sort of nominalism can be approached another way. One can argue that precisely because the forms or what have you are not given in sense then they can be dismissed on empiricist grounds as non-existent. Certainly, for the philosopher who begins by constructing a language to describe the ordinary world given to us in our ordinary sensible experience will find it quite unacceptable to think that one's ontology can tolerate such entities. It follows that for such a one who proposes to also be a nominalist is committed to the view that tropes are blobs. We may very well call them the same or different, but they are the same and different only because we call them by different names. The red in Cebes and the red in Simmias are indeed two, two different tropes, but they are both reds only because that is how we have decided to label them.

A term like 'red' in our language has world-word connections and word-word connections. The term itself corresponds to one of the forms of a Platonist. The world-word connections, the relations of denotation if you 
wish, correspond to the Platonist's relation of participation. But now there is no form to be as it were the connotation of the term, no form to give cognitive content of the form making the form itself the same different as other forms. What replaces such connections are simply the relations that this word has to other words: the cognitive content, in order words, is given by the word-word connections.

Sellars is such a philosopher. Speaking about the tropes which are triangular (in his symbols, tropes which are labelled by the term "T") rather than as we have of tropes that are red, but making the same point, he argues that the (cognitive) meaning of a term is given by its intralinguistic connections to other terms:

although $T^{\prime}$ individual constants are correlated with $T$ objects, the concept of this correlation is not the analysis of what it is for $\mathrm{T}^{\prime}$ individual constants to stand for triangularity, nor does it explain what it is for $\mathrm{T}^{\prime}$ individual constants to denote triangular objects. The correlation between objects and their linguistic pictures must not be confused with the pseudo-relations standing for and denoting. Thus, that 'triangular's stand for triangularity essentially involves the intralinguistic consequence uniformities governed by the consequence rules (axiomatics) of geometrical predicates. ${ }^{6}$

So Cebes-red and Simmias-red, $\operatorname{red}_{1}$ and $\operatorname{red}_{2}$, and all the other red ${ }_{i}$ 's are all Red simply because they are called red; that is, the geometrical sign 'red' which is correlated to the red $d_{i}$ 's is what makes them all Reds, and it makes them Reds not through those world-word correlations but rather through the intralinguistic connections that sign 'red' has to other terms in the language. The objects $\mathrm{red}_{1}$ and $\mathrm{red}_{2}$ are not both red because in and of themselves they are the same in the sense of indistinguishable, that is, objectively the same, where this objective sameness is reflected in language by the occurrence and recurrence of the same sign, but rather they are both red because through the contingencies and accidents of language

${ }^{6}$ Sellars, 1968, p. 128. This account of (cognitive) meaning, has been adumbrated in Sellars, 1953. Compare the discussions of Sellars in Wilson, 2007e; and also Wilson, $2007 \mathrm{f}$.

Sellars' account of meaning as given by inference or consequence connections, that is, as he also puts it, by the axiomatics of the terms involved, shows that he accepts the doctrine that meaning can be conferred by "implicit definition". But this notion of "implicit definition" has little or less to be said for it; cf. "Implicit Definition Once Again" (Wilson, 2007c).

Sellars' concept of (cognitive) meaning is simply unacceptable. Others have offered the same general account of meaning, for example, M. Dummett (cf. Wilson, 2007b, "Dummett on the Origins of Analytic Philosophy"). The criticisms we are making of Sellars apply to these others also. 
they happen to evoke occurrences and recurrences of a certain sign which has certain intralinguistic connections to other signs in the language, where this sign is the one which has the geometrical form 'red'. If we have tropes $a$ and $b$ where

$\mathrm{a}$ is $\mathrm{red}_{1}$, that is, "a is identical to red 1 ", and where

$\mathrm{b}$ is $\mathrm{red}_{2}$, then, on this view of Sellars, to say that

$a$ and $b$ are both Red

is simply to say no more than is said by predicating

' $x$ is $\operatorname{Red}{ }^{\prime}={ }_{D f}$ ' $(x=a \vee x=b) '$

of $a$ and $b$.

It is evident that this is a position that is hard to take seriously. It proposes that the qualitative sameness of things is not objective, that is, not objectively there in the things as we experience them. The properties of things, in other words, are, as we have put it, nothing but blobs, made into things indistinguishable qualitatively in various respects because that is the way we have come to use language: it is the blob theory of properties.

Michael Dummett is another who holds that the world is blobbish. He, like Sellars, rejects Platonism on grounds that we are not acquainted with some world of forms that transcends the world of ordinary things, and is seeking to replace the Platonic account of sameness with a linguistic explanation of sameness, a linguistic account of the similarity of particulars, an account in terms of sense (word-word connections) for the reference of kind terms to different individuals. Dummett has expressed this radical nominalism as follows:

What objects we recognize the world as containing depends upon the structure of our language. Our ability to discriminate, within reality, objects of any particular kind results from our having learned to use expressions, names, or general terms, with which are associated a criterion of identity which yields segments of reality just that shape: we can, in principle, conceive of a language containing names and general terms with which significantly different criteria of identity were associated, and the speakers of such a language would view the world as falling apart into discrete objects in a different way from ourselves [...] for Frege, the world does not come to us articulated in any way; it is we who, by the use of our language (or by grasping the thoughts expressed in that language), impose a structure on it. (Dummett, 1973, pp. 503-504)

Or again, 
The picture of reality as an amorphous lump, not yet articulated into discrete objects, thus proves to be a correct one, so long as we make the right use of it [...] Such a picture corrects the naïve conceptions [...] [which] presupposes that the world presents itself to us already dissected into discrete objects, which we know how to recognize when we encounter them again, in advance of our acquiring any grasp of language at all. (Dummett, 1973, p. 577)

Thus, the samenesses and differences of things is conferred on things by language. It is this that distinguishes Dummett from Stout - and from Berkeley and Hume and also Herbert Spencer. For them, it is resemblance that determines the correct range of application of a term; and resemblance is prior to language. For Dummett, on the contrary, like Sellars, language determines the reference of terms and thereby determines resemblance; language is prior to resemblance: prior to language, there are no oysters or cows, no clouds or shadows, no structure objectively there, no prior fact of any matter, all one "amorphous lump" or pile of blobs. Fraser Cowley rightly asks, he seems to presume rhetorically, «Does he [Dummett] really mean what he seems to mean? Does he really believe it?» (Cowley, 1991, p. 118). But Dummett does seem to believe it ${ }^{7}$. So there you have it: here is what happens to nominalism, to an ontology of tropes - the world turns out to be in itself an "amorphous lump", which might very well also be a pile of blobs. Nominalism leads to a radical subjectivism. It has only to be stated, to be rejected - when I encounter the world in my sense experience of it, I encounter structure and patterns, I do not somehow impose this order on the world.

If it is true, as Sellars once said, that «a naturalist ontology must be a nominalist ontology» (Sellars, 1979, p. 109), and the nominalism is that of his blob theory, then one must conclude that no one can be a naturalist. But it is simply not true: the world as we experience it is simply not a bunch of blobs, and is certainly not an amorphous lump.

We see, then, that the nominalist, in defending his or her claims that the characteristics of things are tropes, has difficulties with accounting for the sameness of tropes. But the case can be made that he or she has difficulties in making clear the notion of trope itself. If he or she has a problem with the sameness of tropes, then he or she equally has a problem with making clear how it is that characteristics of different things which are indistin-

${ }^{7}$ But so does Sellars; cf. Sellars, 1980, pp. 95-124, where he proposes that «universals and laws are correlative, same universals, same laws, different universals, different laws» (p. 104). 
guishable and apparently the same are nonetheless different in some special sense of 'different'.

In fact, I think that here there is a refutation of the nominalist position that is more direct than that of Russell, for example.

The nominalist position claims that there is a sense of 'different' in which properties which are exactly the same in the sense of being indistinguishable are also different. The nominalist has to make good his or her claim that there is such a sense of 'different' by directing our attention to precisely the way in which features that are apparently the same are in this sense different. If he or she cannot show how it is that we can tell in our experience of the world that features are in this sense different, then all that he or she has done is having given us a way of speaking, a syntax if you wish, without giving it an identifiable grounding in the world as we experience it - a grounding given to us in our experience of the world in the way in which sameness in the sense of indistinguishability is given to us in our experience of things. The way of speaking, the syntax, requires a semantics that ties the discourse to an experienceable way the world is.

What does the nominalist say? Consider Stout's statement of the nominalist position. He writes that:

A character characterizing a concrete thing or individual is as particular as the thing or individual which it characterizes. Of two billiard balls, each has its own particular roundness separate and distinct from that of the other, just as the billiard balls themselves are distinct and separate [...] What then do we mean when we say, for instance, that roundness is a character common to all billiard balls. I answer that phrase 'common character' is elliptical. It really signifies a certain general kind or class of characters. To say that particular things share in the common character is to say that each of them has a character which is a particular instance of this kind or class of characters. (Stout, 1930, p. 386)

What we have tried neutrally to call features he refers to as characters, and these characters, even when they are the same in the sense that are indistinguishable, are all nonetheless different: that is why they are all particulars. The problem is to make clear this sense of 'different' by drawing our attention to what it is about the world as we experience it that makes features of the world in this way different.

Our nominalist might try to provide the required interpretation as follows. He or she will say, "This (referring to the colour and only the colour of the one thing) is one instance of (this shade of) red, and that (referring to only the colour of the other diverse thing) is another different ${ }_{3}$ instance of $^{2}$ red". But, as Moore correctly pointed out (Moore, 1966, p. 56), when the 
nominalist, attempting thusly to interpret 'different' in the special way, uses 'this' to refer only to the colour of the one thing, then he or she would not refer to anything different from what he or she refers to with 'that'. For, 'this' and 'that' are used to refer to the same (indistinguishable) colour, and so far as what is presented is concerned, the first conjunct of the nominalist's attempt to interpret 'different' asserts the same as the second conjunct. The nominalist insists that there are two different, yet indistinguishable, instances of the colour, but all that he or she has in fact succeeded in doing is repeating him or herself! He or she certainly has not succeeded in giving a meaning to the word 'different'. Moore puts the point this way:

The refutation perhaps is that: When I say 'This sensibly appears to me to be of that shade' and 'That sensibly appears to me to be of that shade', I am saying the same thing of this \& that. (Moore, 1966, p. 56)

Indeed, Moore puts it quite strongly: of nominalism, Moore exclaims, «Could anything be more absurd!» (ibid.)

The nominalist succeeds in referring twice to one and the same thing. He or she says "The colour of Cebes is one thing" and also that "The colour of Simmias is another, different, thing". But he or she has not shown that there are two things there; all he or she has done is make two references, by means of definite descriptions, to the same thing - the thing to which the one description refers is indistinguishable from the thing to which the other description refers, and he or she has not shown that they are different, in any sense, new or old, of that term. The error is analogous to that of the person who argues that, since we have "This star rises in the morning" and "This star rises in the evening", therefore the morning star is, in a new sense of 'different', different from the evening star. Or again, the error of the nominalist is like the error of the person who argues as follows. We suppose that the terms 'Cebes' and 'Nikita' refer to or denote the same red circular patch. Then there is (this person claims) a sense of 'different', say 'different,', in which the same thing can be different from itself; for, an interpretation for this 'different ${ }_{\mathrm{o}}$ ' can be given in terms of what is presented, by noticing (he or she continues) Cebes and Nikita and saying (following the nominalist's pattern) "Cebes is one instance of this thing, and Nikita is another different $t_{0}$ instance of this same thing". To be sure, this philosopher has twice referred to Cebes. But this is not the same as indicating a feature of what is presented which will provide an interpretation for the proposed use of 'different, 
So nominalism can be rejected by one who, like Bergmann, and like Moore, insists that distinctions in language must reflect distinctions that are to be part of what we encounter in the world as we experience it.

In fact, one can suggest that the nominalist does not construct his or her ontology on the basis of experienced distinctions, but bases it on some $a$ priori principle or other.

One can find such a principle is behind some at least of Stout's reasoning. For, he argues with respect to any two perceived "concrete things", such as our Cebes and Simmias, which one "knows or supposes" to be "locally separate" and therefore different, that one must also "know or suppose" that the colour or shape which the one is experienced as having are also "locally separate" from that colour and the shape which the other is experienced as having; and since the colour and the shape of the one are "locally separate" from the colour and shape of the other, the colour and the shape which the one is experienced as having are different from the colour and the shape that the other is experienced as having (cf. Stout, 1930, pp. 389-390). Stout is in fact arguing that whatever exists, be it a "concrete thing" or a "quality" of a concrete thing, is localized at a place (and time). This Principle of Localization ${ }^{8}$ Stout takes as a premise, a principle that he assumes a priori holds of whatever exists. And so, with regard to two billiard balls, the roundness, the smoothness, and the whiteness of the one has to be "locally separate" and therefore different from the roundness, the smoothness, and the whiteness of the other (cf. Stout, 1930, p. 389).

But, as Moore points out (Moore, 1923, pp. 105-106), while it may be true that no "concrete thing" - a thing like our Cebes or Simmias - can be "locally separate" from itself, it does not follow that a feature like circularity cannot be "locally separate" from itself. Stout may assert that the «same indivisible quality cannot appear separately at different times and places», as he does (Stout, 1930, p. 390), but he gives no reason for taking that to be so: he merely accepts it as a premise from which to argue. But in fact, the same quality can exist "locally separate" from itself: it can do this if it is a quality of two concrete things which are "locally separate". Thus, Cebes and Simmias are "locally separate", and are both red, that quality in the one being indistinguishable from the corresponding quality in the other, and because the red in the one is indistinguishable from the red in the other, that quality does exist "locally separate" from itself.

\footnotetext{
${ }^{8}$ Compare the discussion in Grossmann, 1963.
} 
One must conclude, not that the qualities of "concrete things" are as particular as the things which they characterize, but that these qualities are universals which are simply counterexamples that establish the falsity of the Principle of Localization.

Stout has a second argument for tropes that is also worth looking at. This turns on the principle that «a substance is nothing apart from its qualities» (Stout, 1930, p. 390), and that «there can be no knowledge of it [a substance] which is not knowledge of its characters» (Stout, 1930, p. 391). Given these claims, he argues that

It follows that we cannot distinguish substances from each other without discerning a corresponding distinction between the qualities. (Stout, 1930, p. 391)

So, our things Cebes and Simmias cannot be discerned to be different unless we discern a difference in their qualities. They are both circular, the same diameter of circle, and both are red, the same shade of red. If the qualities of these things are indiscernibly the same, if they are universals, as the realist contends, then there is no discernible difference between them and they would be the same thing. But they are in fact locally separate and therefore are discernibly different. They must therefore be discernibly different through a discernible difference in their qualities. Hence, these qualities must, contrary to the realist, be as particular as the concrete things of which they are qualities: these qualities must be tropes.

But this does not follow at all. Concrete things are indeed complexes, of which the qualities are parts. The realist asserts that those qualities are universals. Stout claims it follows that therefore our Cebes and Simmias could not be different things. It is this which really does not follow. Stout does not allow that complexes may have all the same parts and yet be as wholes discernibly different (Stout, 1930, p. 391). So, it is possible to hold that Cebes and Simmias are complexes which have all their qualities in common and yet are locally separate. One can therefore hold that these two locally separate concrete things share all the same qualities, i.e., that these qualities are universals, and deny that they are tropes 9

It is evident that Stout is relying upon a certain principle which he takes to be an a priori axiom. This is the Principle of the Identity of Indiscernibles:

Entities having exactly the same constituents are identical.

\footnotetext{
${ }^{9}$ Compare Hochberg, 1966.
} 
Given this principle, then two different things cannot have all their constituents in common ${ }^{10}$. But things which are different often do have all their properties in common. There must be something about the things, given the Principle of the Identity of Indiscernibles, that individuates them, some entities that are constituents in them and make them different. This is the so-called Problem of Individuation.

Notice that it is a problem only if one accepts the Principle of the Identity of Indiscernibles.

Be that as it may for the moment, it is evident that Stout and many other philosophers, including Sellars, introduce tropes precisely in order to solve this Problem of Individuation. But tropes won't do: they require a sense of 'different' which they cannot find anything in the world as we experience it that can give it a clear sense. It is this fact that their special sense of 'different', in which their tropes are supposed to be different, cannot be given any meaning in terms that fit properties as we experience them, that led Moore to reject the view as silly: «could anything be more absurd», he says.

But now the properties are universals, and hence, if one accepts the Principle of the Identity of Indiscernibles, there must be present in the two qualitatively or indiscernibly the same things which are nonetheless diverse or locally separate - things such as our Cebes and Simmias - some constituent in each such thing - some constituent other than the qualities which are in themselves just different and which therefore individuate the things. These entities are not universals and are therefore not among the properties of the things, all of which are universals; they are, rather, simple particulars. Since they are there simply to make the two different things different, they are not properties or qualities, and are therefore said to be in and of themselves, quite bare ${ }^{11}$. These bare particulars do nothing but individuate.

Here, for example, is Allaire. He considers two diverse discs with all their (non-relational) properties in common.

When presented together, [the two discs] are presented as numerically different. That difference is presented as is their sameness with respect to space, (shade of) color, and so on. What counts for that difference are numerically different individuals. No character or group of characters can do that. Thus, to say that they are individuals is to say that things may be merely numerically different. No matter

${ }^{10}$ One assumes here the argument of Russell, that relations do not individuate; cf. Russell, 1963. Cf. also Hochberg, 2002.

${ }^{11}$ But one must qualify this notion of bareness: cf. Wilson, 2007c. 
what description one proposes, the numerical difference of two things which are alike in all (non-relational) respects must be accounted for. (Allaire, 1963, p. 4) ${ }^{12}$

Notice the starting point: the two things are presented as different, that is, different in the sense of being diverse in space, locally separate. Here the difference in the sense of diversity is given to one in acquaintance. But then we are asked, what "accounts for" this difference? We are now taken to be assuming that such diversity is somehow philosophically problematic. This problem that has now appeared requires solution: an entity must be found, or rather must be there, whether found or not, which does the accounting. This entity which does that is an "individual" which is taken to be a constituent of the things, there in addition to the (non-relational) properties which are present in the things. Allaire is clearly assuming something like the Principle of the Identity of Indiscernibles to justify the inference to the individuals which account for the difference. And, now, given the presence of the individuals as constituents, the relation of diversity holding between the things can be defined in terms of the difference among the constituents. But notice that one is defining 'diverse' in terms of 'different' where the latter is, Allaire is suggesting, not given or not wholly given in our experience of the world. To be sure, the various properties in the things are different in the sense of distinguishable, and that is, as we have insisted, a sense of 'different' rooted in our experience of things: we use descriptive constants of our perspicuous language to refer to properties on the basis of the experienced distinguishability and indistinguishability of features of things in the world. But Allaire would have it that we should, on the one hand, understand that the individuals are also different from the other constituents of the things, but, on the other hand, also understand that this sense of 'different' cannot be rooted in our experience of the world. For individuals or bare particulars are introduced into his ontology not because they can be discerned as features of things, but for dialectical reasons that have nothing to do with discerning in the world further features of things. How then can one say that the individuals Allaire is defending are different in the sense of 'distinguishable'? Allaire is taking for granted that 'different' is univocal, and that it acquires what meaning it has independently of any attempt to ground its use in our experience of the world.

${ }^{12}$ Compare Bergmann: «Bare particulars neither are nor have natures. Any two of them are not intrinsically but only numerically different. That is their bareness. It is impossible for a bare particular to be "in" more than one ordinary thing [...] A bare particular is a mere individuator [...] It does nothing else» (Bergmann, 1967, pp. 2728). 
For one who wishes to develop an ontology that fits the world given to one in sensible experience, that is unacceptable.

But Allaire also recognizes this point. He goes on:

To claim that both [the two things] are collections of literally the same universals does not account for the thisness and thatness which are implicitly referred to in speaking of them as two collections. That is, the two collections of characters - if one persists in speaking this way - are, as presented, numerically different. Clearly, therefore, something other than a character must also be presented. That something is what proponents of the realistic analysis call a bare particular. (Allaire, 1963, p. 4)

Allaire is clearly arguing that we really are acquainted in experience with bare particulars: we must be acquainted with them because they must be there. But none of this follows ${ }^{13}$. As Hochberg has made clear, neither of these 'musts' need be accepted. First, that these entities must be presented in experience because they must be there, does not follow ${ }^{14}$. Second, because the two things are diverse or locally separate, it does not follow that that diversity must be "accounted for" by a constituent: it could be that the diversity is primitive and unanalyzable, that the two things are simply diverse - that is, Allaire's argument rests on the Principle of the Identity of Indiscernibles and we have been given no reason for accepting that ${ }^{15}$. As Hochberg puts it,

13 Some argue that none of this matters: who nowadays worries about acquaintance? Thus, J.P. Moreland, 1998 argues that it does not matter that Allaire fails to establish that we are acquainted with the bare particulars that he establishes on dialectical grounds must be there: «Today, most philosophers would not place the type of constraints on analytic ontology that was present in Bergmann's day. The real issue for bare particulars is whether or not the arguments for and against them are sufficient to justify their adoption as a solution to individuation, not whether they are sense perceptible» (Moreland, 1998, p. 256). But for some of us, those who are still empiricists, and do ontology in a framework established by a Principle of Acquaintance, acquaintance does still matter: dialectics is not, and cannot, be everything. Acquaintance is still important even if Allaire's argument is, as Moreland suggests, unsuccessful.

However, for some of the dialectics, cf. Moreland, 2001; Hoffmann - Rosenkranz, 1994; Metz, 2001; Loux, 1998; Oaklander - Rothstein, 2000; Davis, 2003, and Davis, 2004.

${ }^{14}$ Laird Addis, however, has suggested otherwise, (cf. Addis, 1967) or at least has suggested that it does not matter: bare particulars must exist, and therefore whether we are acquainted with them is an irrelevant issue. But it is not, and could not be, an irrelevant issue for one doing ontology within the framework of a Principle of Acquaintance.

${ }^{15}$ Compare Hochberg, 2002, pp. 132-134; see also Hochberg, 1966. 
one can reasonably hold that different objects are simply different objects - there is nothing that is needed to, or indeed can, non-trivially, account for such difference. Nor need we seek to "analyze" such objects as being bundles of compresent qualities, substrata exemplifying qualities, or anything else. (Hochberg, 2002, p. 132)

Hochberg infers from this that there is no need to suppose that there are particulars as the constituents of things. That would follow only if we do not discern them as constituents of things. Hochberg is correct: the argument that they must be discernible is unsound; however it does not follow that they are not among the entities that we can distinguish in experience as the constituents of things.

I would suggest that there in fact are discernible in things features which play the role of particulars. We have already noted them as existents in our little model universe. These entities, to which we previously directed our attention, are the expanses or areas in the patches in our model universe. Oddly enough, Stout would seem to agree. At least, he would agree that these entities do exist. For, in his description of sensations that he once gave, he notes that besides qualities as features or discernible attributes of sensations there is a "further attribute» that is "variously described as 'extensity', 'extensiveness, 'voluminousness', 'diffusion', or 'spreadoutness'» (Stout, 1929, p. 127). William James also directed our attention to this feature of things: he notes that «this element [extensity] [is] discernible in each and every sensation»; and comments that

extensity, being an entirely peculiar kind of feeling indescribable except in terms of itself, and inseparable in actual experience from some sensational quality which it must accompany, can itself receive no other name than that of sensational element. (James, 1890, pp. 135-136)

It is this element or feature that Bergmann called the "area" in a thing (Bergmann, 1964, p. 288).

Ordinary concrete things, the patches of our model universe, for example, are individual things, we have this image and that. A concrete thing, a this or a that, is something complex. It has properties and these properties are with each other. An ordinary thing is thus a group of properties that are with one another. But it is not just a group of properties that are with one another: there is also the area that is in the thing. An ordinary concrete thing is thus a group of properties together with an area; and these entities are with one another forming the thing. This feature, an area, is discernible in each complex of properties, distinguishable from the other features in the complex, and, moreover, each such area is distinguishable from every other such area. 
One therefore has one thing - one area. Clearly, then, these features of things can serve the role of the individuators or bare particulars of Allaire and Bergmann.

Moreover, while it is true, as Hochberg argued, that things as complexes or wholes can be taken to be unanalyzably diverse, and that there is no necessity, based on something like the Principle of the Identity of Indiscernibles, for one to accept that there are such things as bare particulars, nonetheless it is still true that there are experienced and distinguishably different features of things which play the role of individuators and which therefore can be used to analyze the diversity of things in terms of the distinguishability of constituents of things. One cannot argue dialectically that there must be bare particulars, but for all that there are such entities contingently so if you wish - but still there as distinguishable parts of the world as we experience it.

And so in our model universe with which we started, we noted that there are two expanses which are $\mathrm{R}$, red, and another, third expanse which is green. These expanses are distinguishable from the features we have already recorded in our language as properties, and are among themselves distinguishable one from another. Let us therefore have as before the constants ' $\mathrm{X}$ ', ' $\mathrm{Y}$ ' and ' $\mathrm{Z}$ ' pick out these three further features of this world.

These expanses go with the other features red ("R"), green ("G"), circle ("C") and square ("S") in the world in several ways. We recorded these ways the world is by the sentences

$$
\mathrm{W}(\mathrm{X}, \mathrm{R}, \mathrm{C}) \quad \mathrm{W}(\mathrm{Y}, \mathrm{R}, \mathrm{C}) \quad \mathrm{W}(\mathrm{Z}, \mathrm{G}, \mathrm{S})
$$

These sentences, through the ways in which the terms are organized into these sentences, picture the ways in which features go together or are with one another in our model world. Cebes is one of the ways in which the features go together in our model world, Simmias is another, and Socrates is a third, and these ways of going together, these wholes, are individuated by the expanses or areas labelled $\mathrm{X}, \mathrm{Y}$, and $\mathrm{Z}$ : these three distinguishable entities are the bare particulars in these three things, where the other distinguishable features - red, green, circle and square - are the universals in the three things.

And now let us return to our positivist, constructing his or her language with descriptive constants to mark features of the world as experienced. Many have found it odd that this philosopher includes bare particulars among the entities of the world we are said to experience - do we really experience these things? or are they something we have simply argued ourselves into, put there in the world in spite of what we experience? We 
now see clearly the answers to these questions. And in seeing that, we recognize that we really should not be surprised that this philosopher discovers among the elements of his or her ontology those entities that have been called "bare particulars": they are not so strange after all, not nearly so strange as tropes and certainly not blobs - the world we experience really does contain these entities, which therefore deserve a place in our ontology.

Fred Wilson

Department of Philosophy

University of Toronto

Toronto, $O N$

Canada M5R 2M8

fwilson@chass.utoronto.ca

\section{REFERENCES}

Addis, L. (1967), "Particulars and Acquaintance", Philosophy of Science, XXIV, pp. 251-259.

Allaire, E.B. (1963), "Bare Particulars", Philosophical Studies, XIV, pp. 1-8.

Allaire, E.B. et al. (1963), Essays in Ontology, Nijhoff, The Hague.

Bergmann, G. (1942), "An Empiricist Schema of the Psychophysical Problem", Philosophy of Science, IX, pp. 72-91.

- (1944), "Holism, Historicism, and Emergence", Philosophy of Science, XI, pp. 209221.

- (1964), "Synthetic A Priori", in Id., Logic and Reality, University of Wisconsin Press, Madison (WI), pp. 272-301.

- (1967), Realism, University of Wisconsin Press, Madison (WI).

Cowley, F. (1991), Metaphysical Delusion, Prometheus Books, Buffalo (NY).

Davis, R.B. (2003), “'Partially Clad' Bare Particulars Exposed”, Australasian Journal of Philosophy, LXXXI, pp. 534-548.

- (2004), "The Brave New Bare Particularism", Modern Schoolman, LXXXI, pp. 266-273.

Dummett, M. (1973), Frege: Philosophy of Language, Duckworth, London.

Grossmann, R. (1963), “Conceptualism”, in Allaire et al., 1963, pp. 40-49.

Hochberg, H. (1966), "Things and Qualities", in D. Merrit - K. Capitan, eds., Metaphysical Explanation, University of Pittsburgh Press, Pittsburgh, pp. 82-97. 
- (1984), "Russell's Proof of Realism Re-Proved", in Id., Logic, Ontology and Knowledge, Philosophia Verlag, München, pp. 196-203.

- (2002), "Individuation and Individual Properties: A Study of Metaphysical Futility", Modern Schoolman, LXXIX, pp. 107-134.

Hoffmann, J. - Rosenkrantz, G. (1994), Substance and Other Categories, Cambridge University Press, Cambridge.

James, W. (1890), Principles of Psychology, Henry Holt, New York, vol. II.

Lewis, D. (1991), Parts of Classes, Blackwell, Oxford.

Loux, M. (1998), Metaphysics: A Contemporary Introduction, Routledge, London.

Metz, D.W. (2001), "Individuation and Instance Ontology", Australasian Journal of Philosophy, LXXIX, pp. 45-61.

Moore, G.E. (1923), "Are the Characteristics of Things Universal or Particular?" Proceedings of the Aristotelian Society, Supplementary Volume III , pp. 95-113.

- (1966), Lectures on Philosophy, ed. by C. Lewy, Allen and Unwin, London.

Moreland, J.P. (1998), "Theories of Individuation: A Reconsideration of Bare Particulars", Philosophical Quarterly, LXXIX, pp. 251-263.

- (2001), Universals, Acumen, Chesham.

Oaklander, N. - Rothstein, A. (2002), "Loux on Particulars: Bare and Concrete", Modern Schoolman, LXXVIII, pp. 97-102.

Plato (1987), Theatetus, Engl. transl. with an essay by Robin Waterfield, Penguin, London.

Russell, B. (1956), "On the Relations of Universals and Particulars”, in Id., Logic and Knowledge, ed. by R.C. Marsh, Allen and Unwin, London, pp. 103-124.

Sellars, W. (1953), "Inference and Meaning”, Mind, N.S. LXII, pp. 313-338.

- (1968), Science and Metaphysics, Routledge, London.

- (1979), Naturalism and Ontology, Ridgeview, Atascadero (CA).

- (1980), "Concepts as Involving Laws and Inconceivable Without Them", in Id., Pure Pragmatics and Possible Worlds: The Early Essays of Wilfrid Sellars, ed. with introd. by J. Sicha, Ridgeview, Atascadero (CA), pp. 95-124.

Stout, G.F. (1929), Manual of Psychology, W.B. Clive, London, $4^{\text {th }}$ ed.

- (1930), "The Nature of Universals and Proposition", in Id., Studies in Philosophy and Psychology, Macmillan, London, pp. 384-404.

Wilson, F. (2007a), "Universals, Particulars and Tropes: The Role of a Principle of Acquaintance in Ontology", in Wilson (2007e), pp. 363-398.

- (2007b), "Dummett's History: Critical Review of Michael Dummett's Origins of Analytical Philosophy”, in Wilson (2007e), pp. 683-726.

— (2007c), “Implicit Definition Once Again”, in Wilson (2007e), pp. 653-682. 
- (2007d), "Bareness, as in 'Bare Particular': Its Ubiquity", in Wilson (2007e), pp. 329-362.

- (2007e), Acquaintance, Ontology and Knowledge, Ontos Verlag, Frankfurt a.M.

- (2007f), "Placing Bergmann", in L. Addis - G. Jesson - E. Tegtmeier, eds., Ontology and Analysis: Essays and Recollections about Gustav Bergmann, Ontos Verlag, Frankfurt a.M., pp 185-276. 
